\title{
COVID-19 and Gestational Diabetes: A Systematic Review
}

\author{
Vitor Fernando Bordin Miola ${ }^{1}$, Ana Rita de Oliveira dos Santos ${ }^{1}$, \\ Bárbara de Oliveira Zanuso'ㅗ, Maria Eduarda Guelfi Pinto ${ }^{1}$, João Paulo Galleti Pillon', \\ Jesselina Francisco dos Santos Haber ${ }^{1}$, Ricardo de Alvares Goulart ${ }^{2}$, \\ Sandra Maria Barbalho ${ }^{1,2,3^{*}}$
}

${ }^{1}$ Department of Biochemistry and Pharmacology, School of Medicine, University of Marília (UNIMAR), São Paulo, Brazil ${ }^{2}$ Postgraduate Program in Structural and Functional Interactions in Rehabilitation, University of Marilia (UNIMAR), São Paulo, Brazil

${ }^{3}$ Department of Biochemistry and Nutrition, Faculty of Food Technology of Marília, São Paulo, Brazil

Email: *smbarbalho@gmail.com

How to cite this paper: Miola, V.F.B., de Oliveira dos Santos, A.R., de Oliveira Zanuso, B., Pinto, M.E.G., Pillon, J.P.G., dos Santos Haber, J.F., de Alvares Goulart, R. and Barbalho, S.M. (2020) COVID-19 and Gestational Diabetes: A Systematic Review. Journal of Diabetes Mellitus, 10, 236-244. https://doi.org/10.4236/jdm.2020.104019

Received: October 31, 2020

Accepted: November 21, 2020

Published: November 24, 2020

Copyright $\odot 2020$ by author(s) and Scientific Research Publishing Inc. This work is licensed under the Creative Commons Attribution International License (CC BY 4.0).

http://creativecommons.org/licenses/by/4.0/

\begin{abstract}
In March 2020, the World Health Organization declared a pandemic state in response to the number of infected and killed by COVID-19. Gestational diabetes (GD) is characterized by physiological changes making pregnant women even more vulnerable to viral respiratory infections, such as SARS-CoV-2. For these reasons and due to the restriction of data related to DMG and the involvement by COVID-19, the importance of raising information about these two conditions is evident. Therefore, this study aimed to perform a literature review about the complications of COVID-19 in patients with GD. MEDLINE-PubMed, EMBASE, and Scielo databases were searched and followed the PRISMA guidelines. Only four studies were included in the systematic review. The complications and mortality are more significant in pregnant women with diabetes since hyperglycemia promotes immune changes in the inflammatory state and worsens insulin resistance. The imbalance in the immune response favors the development of infections, the most likely being viral respiratory infections. On the other hand, other studies show insufficient recent evidence to indicate that pregnant women are more susceptible to infection with severe acute coronavirus respiratory syndrome. There are divergences between studies concerning complications related to COVID-19 in patients with GD. In view of this scenario and from the information obtained, it is noted that the literature is scarce regarding the worsening of COVID-19 in patients with GD. Therefore, it is necessary to continue research on these mechanisms that may justify their correlation.
\end{abstract}




\section{Keywords}

COVID-19, Diabetes Mellitus, Gestational Diabetes, Hyperglycemia

\section{Introduction}

In December 2019, in the Chinese city of Wuhan, a variety of viruses from the Coronavirus group emerged and was named SARS-CoV-2, due to the Severe Acute Respiratory Syndrome Coronavirus. In March 2020, the World Health Organization (WHO) declared a pandemic state in response to the number of infected and killed by COVID-19, a disease caused by the virus [1] [2]. Viral infection induces inflammatory responses through a cascade of cytokines and growth factors, which can damage lung tissue and are responsible for the Acute Respiratory Syndrome [3] [4].

Some conditions predispose to the severe form of the disease. This is possibly due to an impairment of the immune response. Type 2 diabetes mellitus (DM2), in particular, seems to be associated with a worse prognosis once hyperglycemia, in addition to the association with the formation of advanced glycation end products (AGES) result in oxidative stress and inflammatory process that can also favor viral replication [5].

Gestational diabetes (GD), like DM2, is characterized by fasting hyperglycemia as a consequence of resistance to the action of insulin. This resistance occurs due to the production of hyperglycemic hormones and enzymes that degrade insulin, coming from the placenta. During GD, physiological changes, such as immune dysfunction and the promotion of inflammatory factors, make pregnant women even more vulnerable to viral respiratory infections, such as SARS-CoV-2 [6] [7]. For these reasons and due to the restriction of data related to DMG and the involvement by COVID-19, the importance of raising information about these two conditions is evident.

Therefore, this study aimed to perform a literature review about the complications of COVID-19 in patients with GD.

\section{Methods}

\subsection{Data Source}

This review was carried out at MEDLINE-PubMed (National Library of Medicine, National Institutes of Health), EMBASE, and Scielo databases were searched and following the PRISMA (Preferred Reporting Items for a Systematic Review and Meta-Analysis) guidelines. This review aimed to answer the following focal question: Does COVID-19 worsen women's health with gestational diabetes?

\subsection{Search}

This research included articles published in the last year (March 2020 to October 
2020) and considered clinical trials, double-blind, randomized, placebo-controlled studies, retrospective case-control studies, and studies with animal models. The combination of terms used for the search was: COVID-19 or Sars-Cov-2 and gestational diabetes.

\subsection{Eligible Criteria and Study Selection}

This review included studies that demonstrated the effects of COVID-19 in women with gestational diabetes. Exclusion criteria were articles not in English, literature reviews, abstracts, and letters to the editor.

\subsection{Data Extraction}

Two authors searched the databases independently according to the descriptors and inclusion and exclusion criteria. The results were extracted from eligible articles that indicated the author, date, sample size, study design, and gender.

\section{Results and Discussion}

Based on the inclusion and exclusion criteria used for this work, four studies showed the relationship of COVID-19 in DMG patients (Figure 1). Together, these studies included 1101 women aged 15 to 54 years. These studies were carried out in the following countries: China, the United States, France, and Iran. Table 1 shows the characteristics of these studies.

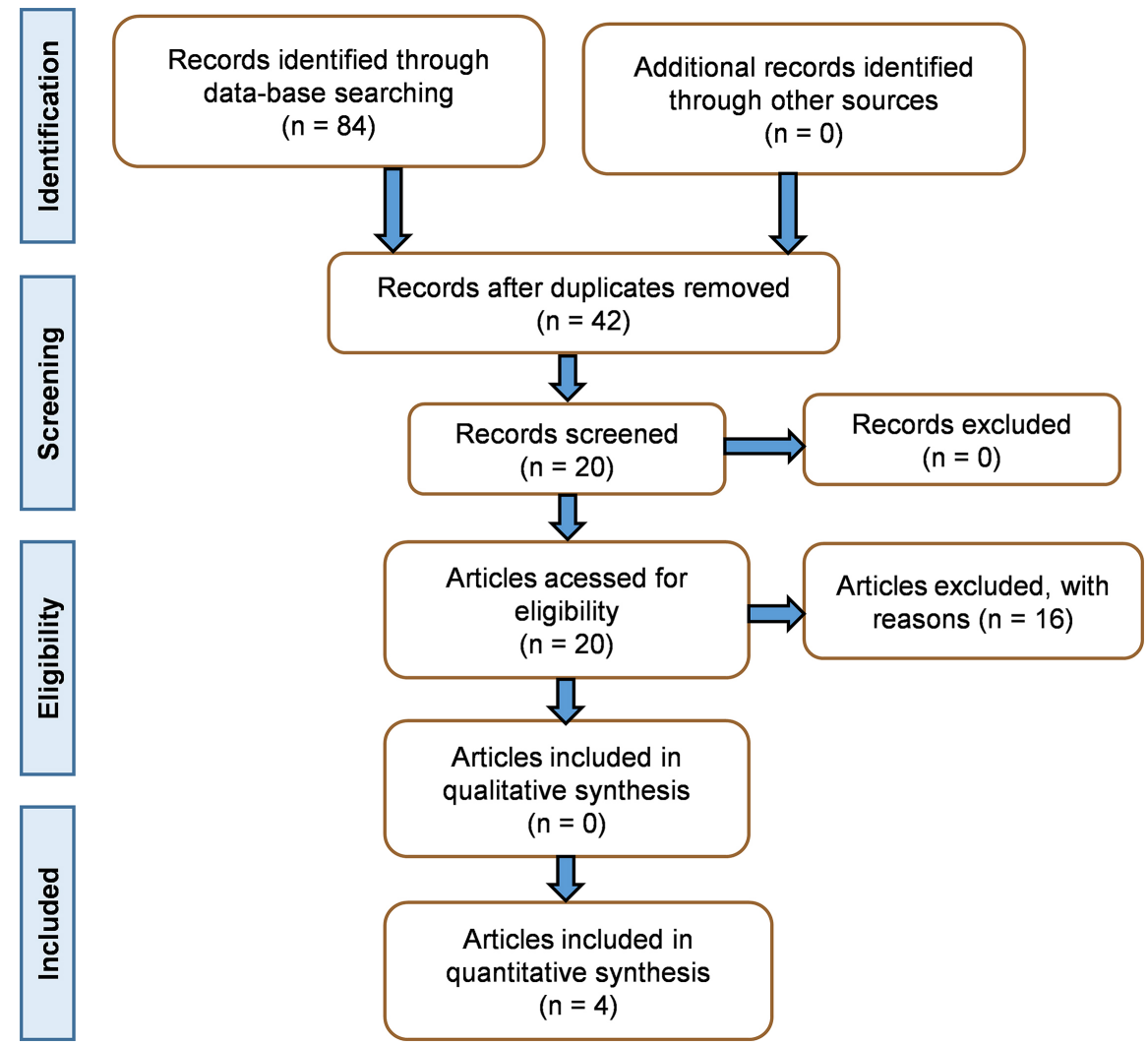

Figure 1. Flow chart showing the selection of the studies [8]. 
Table 1. Associations between COVID-19 and gestational diabetes.

\begin{tabular}{|c|c|c|c|}
\hline Reference & Type of the study & Results & Conclusions \\
\hline $\begin{array}{c}\text { Panagiotakopoulos } \\
\text { et al. }[9]\end{array}$ & $\begin{array}{l}\text { A study with } 105 \text { hospitalized } \\
\text { pregnant women with } \\
\text { SARS-CoV-2 infection. }\end{array}$ & $\begin{array}{l}13.3 \% \text { of pregnant women were admitted } \\
\text { to the ICU. Among them, six required } \\
\text { mechanical ventilation, and one died. } \\
\text { The number of pregnant women with } \\
\text { GD was } 15.2 \% \text {. Also, } 36.2 \% \text { had } \\
\text { pre-pregnancy obesity. }\end{array}$ & $\begin{array}{l}\text { Despite the higher percentages of GD } \\
\text { and pre-pregnancy obesity in pregnant } \\
\text { women hospitalized for COVID-19 } \\
\text { without obstetric reason, more } \\
\text { information is needed to understand } \\
\text { the effects caused by SARS-CoV-2 } \\
\text { during pregnancy and its complications. }\end{array}$ \\
\hline Pirjani et al. [10] & $\begin{array}{l}\text { Prospective cohort study } 199 \text { pregnant } \\
\text { women (15 - } 46 \text { years old), } 66 \text { pregnant } \\
\text { women infected with SARS-CoV-2 } \\
\text { and } 133 \text { uninfected pregnant women } \\
\text { who formed the control group. }\end{array}$ & $\begin{array}{l}\text { There was no significant relationship } \\
\text { between COVID-19 infection and } \\
\text { complications from comorbidities, } \\
\text { including GD. Despite this, infected } \\
\text { patients had a higher percentage of } \\
\text { admission to the ICU compared } \\
\text { to the control group. }\end{array}$ & $\begin{array}{l}\text { No significant differences were observed } \\
\text { between clinical manifestations and } \\
\text { pregnancy complications in infected } \\
\text { and uninfected women. }\end{array}$ \\
\hline Kayem et al. [11] & $\begin{array}{l}\text { Series of cases involving } 617 \text { pregnant } \\
\text { women in } 33 \text { maternity centers } \\
\text { in France were diagnosed with } \\
\text { COVID-19, of which } 497(80.6 \%) \\
\text { were symptomatic. }\end{array}$ & $\begin{array}{l}\text { Of the women who were associated } \\
\text { with a severe form of the disease, } \\
\text { who had comorbidities such as DMG, } \\
\text { it was seen that one died, and } 85.3 \% \\
\text { of these women gave birth, } 79.3 \% \\
\text { of whom were premature. }\end{array}$ & $\begin{array}{l}\text { The study found that those women } \\
\text { who had comorbidities such as DMG } \\
\text { had COVID-19 more severely. } \\
\text { Critically ill women had a high } \\
\text { rate of premature birth. }\end{array}$ \\
\hline Sun et al. [12] & $\begin{array}{l}\text { Case-control study with } 60 \text { of } \\
\text { pregnant women confirmed to } \\
\text { have COVID-19 and } 120 \text { controls. }\end{array}$ & $\begin{array}{l}\text { Compared to the control group, } 21.67 \% \\
\text { of the pregnant women in the case group } \\
\text { were diagnosed with GD. They presented } \\
\text { high levels of neutrophils and low levels } \\
\text { of total protein. White blood cell levels } \\
\text { of pregnant women with COVID-19 } \\
\text { without diabetes were higher than the } \\
\text { levels of the diabetes control group. }\end{array}$ & $\begin{array}{l}\text { The study shows that chronic diseases } \\
\text { may potentialize the inflammatory } \\
\text { response to COVID-19. The focus on } \\
\text { diabetes is hyperglycemia, which can } \\
\text { increase the inflammatory response plus } \\
\text { to compromise the regeneration's ability } \\
\text { of the liver, causing it liver injury. }\end{array}$ \\
\hline
\end{tabular}

GD: Gestational Diabetes; ICU: Intensive Care Unit.

The review by McIntyre [13] reports that there is insufficient recent evidence to indicate that pregnant women are more susceptible to infection with severe acute respiratory coronavirus syndrome (SARS-Cov-2). Likewise, the case report conducted by Smati et al. [14] narrates about a 36-year-old pregnant woman with GD from the Democratic Republic of Congo hospitalized by COVID-19. Although pregnancy predisposes to an increased chance of diabetic ketoacidosis due to the placenta's hormonal properties, the study does not clarify whether COVID-19 worsens this condition.

In the same perspective, Gidlöf et al. [15], through the report of a 34-year-old GD woman, sought to establish the maternal-fetal complications implied by COVID-19 manifested by the patient. Although the patient showed some characteristic clinical signs, such as pneumonia, the twins were born in good condition, condition supported by negative nasopharyngeal tests for COVID-19, as well as a sample of breast milk. 
One of the hypotheses that explain that vertical transmission of the SARS-CoV-2 virus is unlikely is that the angiotensin-converting enzyme 2 (ECA2), which works as a receptor for the virus, has no significant expression in the cells of the interface maternal-fetal. Moreover, transmission via breastfeeding was also absent due to the virus's non-detection in breast milk samples. However, infection through contact should not be neglected in these cases, and the distance between mother and baby is safer during the period of transmissibility [16].

The cohort study performed by Pirjani et al. [10] compared possible differences between pregnant women infected with SARS-CoV-2 and uninfected women. Four of the infected patients required care in the ICU, but there was no need for intubation, mechanical ventilation, and they did not have acute respiratory syndrome. Only one baby was infected, but it was not possible to determine the cause of transmission. Therefore, it was not possible to establish differences in prognosis between infected and uninfected women.

On the other hand, the study of Torlone et al. [17] shows that adverse endpoints and mortality are higher in pregnant women with diabetes, precisely because scientific evidence indicates that hyperglycemia promotes immune changes such as the inflammatory state that worsens insulin resistance. Moreover, in the immune response, the most likely infections are viral respiratory infections, which do not have data to confirm the vertical transmission of COVID-19. Therefore, the current pandemic context requires greater care for the diagnosis and treatment of gestational diabetes.

In a study carried out using data from 33 French maternity hospitals, in which in all analyzed cases the women were pregnant and diagnosed with COVID by the RT-PCR test, it was shown that women with diseases such as GD, pre-eclampsia, old age, or age over 35 and obesity, as well as preexisting diabetes, are more likely to have COVID comorbidities [11].

In the study of Panagiotakopoulos et al. [9] performed in eight health centers in the USA, the hospitalization of 105 pregnant women identified with SARS-CoV-2 was evaluated. Among them, 59\% were hospitalized for obstetric reasons and 41\%, due to COVID-19 and who had no obstetric reasons. In the latter group, a higher prevalence of GD (25.6\%) and pre-pregnancy obesity (44.2\%) was found among those hospitalized for obstetric reasons. Besides, the prevalence of premature and stillbirth was higher among women with SARS-CoV-2 than in uninfected women.

In another perspective, in an analysis of post-COVID-19 management in the diagnosis of GD in the protocols of the United Kingdom, Canada, and Australia, it is recommended to restrict the Oral Glucose Tolerance Tests (TOTG), performed between 24 and 32 gestational weeks, in order to reduce exposure to COVID-19 in the collection centers, monitoring and guiding pregnant women with alternative resources such as telemedicine [13]. However, the restriction of oral glucose tolerance test (OGTT) would result in a reduction in the frequency of diagnosis of GD in studies, from $81 \%$ to $2.5 \%$ in the United Kingdom, from 
$82 \%$ to $1.7 \%$ in Canada, and from $25 \%$ to $12 \%, 7 \%$ in Australia.

A case-control by Sun et al. [9] at Wuhan shows, through laboratory and clinical diagnosis, that the number of neutrophils in GD women with COVID-19 was higher than the pregnant COVID-19 patients without any chronic disease. The data also confirm that lymphocytopenia levels among pregnant women with COVID-19 were higher (43.33\%) in relation to the control group (15.83\%). Hyperglycemia is a diabetes comorbidity which causes oxidative stress, can increase inflammatory response and compromise the liver's regeneration [12].

In another study conducted at a London tertiary hospital, the OGTT restriction guidelines published by the Royal College of Obstetricians and Gynecologists during the pandemic impacted the reduction in the rate of detection of GD

Besides that, van Gemert et al. [18] points out that guidelines have been revised to reduce the number of pregnant women with GD exposed to the virus.

In a narrative review of the temporary changes in clinical guidelines performed by Nouhjah et al. (2020), there is a consensus to postpone postpartum screening from 4 to 12 weeks or delay from 6 to 12 months after birth until the end of the COVID-19 crisis. These changes aim to reduce the number of consultations and length of stay in the hospital for pregnant women, in addition to the risks of exposure, since pregnant women with diabetes constitute a population at risk for severe forms of COVID-19 [19] [20] [21] [22]. Also, all women should be encouraged to lead a healthy lifestyle during pregnancy, given the risk that gestational diabetes will not be detected with changes in screening protocols, in addition to maintaining basic precautionary measures such as hand hygiene, wearing masks, and social detachment [23] [24].

Changes in the management of post-COVID-19 GD diagnosis were another aspect discussed in the studies discussed above. Most of these changes prioritize restricting oral glucose tolerance tests, as well as reducing visits to collection centers, and hospital stays in order to deprive patients of exposure to the virus. In this context, it is recommended to adopt healthy lifestyle habits, given the risk that GD will not be detected with changes in screening protocols and telemedicine monitoring.

\section{Conclusions}

There are divergences between studies concerning complications related to COVID-19 in patients with GD. Although hyperglycemia and pregnancy are aggravating factors for infections, especially viral respiratory infections, there is no scientific evidence to clarify the mechanisms that promote the severe form of COVID-19 when present with GD. Despite this, some authors have shown no substantial complications in pregnant women infected with SARS-CoV-2 and who had comorbidities such as DMG. In these cases, the severe acute respiratory syndrome was not present. However, clinical conditions, such as pneumonia, were manifested. There was also no evidence of vertical transmission of COVID-19.

Therefore, further studies are needed to elucidate the consequences of the 
contamination of this virus in GD women.

\section{Conflicts of Interest}

The authors declare no conflicts of interest regarding the publication of this paper.

\section{References}

[1] Rudrapal, M., Khairnar, S.J., Borse, L.B. and Jadhav, A.G. (2020) Coronavirus Disease-2019 (COVID-19): An Updated Review. Drug Research, 70, 389-400.

https://doi.org/10.1055/a-1217-2397

[2] Neiva, M.B., Carvalho, I., Costa Filho, E.D.S., Barbosa-Junior, F., Bernardi, F.A., Sanches, T.L.M., Oliveira, L.L., Lima, V.C., Miyoshi, N.S.B. and Alves, D. (2020) Brazil: The Emerging Epicenter of COVID-19 Pandemic. Revista da Sociedade Brasileira de Medicina Tropical, 53, e20200550.

https://doi.org/10.1590/0037-8682-0550-2020

[3] de Lucena, T.M.C., da Silva Santos, A.F., de Lima, B.R., De Albuquerque Borborema, M.E. and de Azevêdo Silva, J. (2020) Mechanism of Inflammatory Response in Associated Comorbidities in COVID-19. Diabetes \& Metabolic Syndrome, 14, 597-600. https://doi.org/10.1016/j.dsx.2020.05.025

[4] Tovani-Palone, M.R., Lacagnina, S. and Desideri, L.F. (2020) Number of COVID-19 Patients Classified as Cured: An Imminent Danger for the Population. Einstein (Sao Paulo, Brazil), 18, eCE6146. https://doi.org/10.31744/einstein_journal/2020CE6146

[5] Matias, J.N., Campanari, G.S.D.S., Souza, G.A.D., Lima, V.M., Tofano, R.J., Detregiachi, C.R.P. and Barbalho, S.M. (2020) Metabolic Syndrome and COVID-19. AIMS Bioengineering, 7, 242-253. https://doi.org/10.3934/bioeng.2020021

[6] D’Ambrosi, F., Rossi, G., Soldavini, C.M., Maggi, V., Cetera, G.E., Carbone, I.F., Di Martino, D., Di Maso, M. and Ferrazzi, E. (2020) Management of Gestational Diabetes in Women with a Concurrent Sars-Cov-2 Infection, Experience of a Single Center in Northern Italy. International Journal of Gynaecology and Obstetrics: The Official Organ of the International Federation of Gynaecology and Obstetrics. https://doi.org/10.1002/ijgo.13434

[7] Gortazar, L., Goday, A., Flores-Le Roux, J.A., Sarsanedas, E., Payà, A., Mañé, L., Pedro-Botet, J. and Benaiges, D. (2020) Trends in Prevalence of Pre-Existing Diabetes and Perinatal Outcomes: A Large, Population-Based Study in Catalonia, Spain, 2006-2015. BMJ Open Diabetes Research \& Care, 8, e001254. https://doi.org/10.1136/bmjdrc-2020-001254

[8] Moher, D., Liberati, A., Tetzlaff, J. and Altman, D.G. (2009) Preferred Reporting Items for Systematic Reviews and Meta-Analyses: The PRISMA Statement. Annals of Internal Medicine, 151, 264-269.

https://doi.org/10.7326/0003-4819-151-4-200908180-00135

[9] Panagiotakopoulos, L., Myers, T.R., Gee, J., Lipkind, H.S., Kharbanda, E.O., Ryan, D.S., Williams, J.T.B., Naleway, A.L., Klein, N.P., Hambidge, S.J., et al. (2020) SARS-CoV-2 Infection among Hospitalized Pregnant Women: Reasons for Admission and Pregnancy Characteristics-Eight U.S. Health Care Centers, March 1-May 30, 2020. MMWR. Morbidity and Mortality Weekly Report, 69, 1355-1359. https://doi.org/10.15585/mmwr.mm6938e2

[10] Pirjani, R., Hosseini, R., Soori, T., Rabiei, M., Hosseini, L., Abiri, A., Moini, A., Shizarpour, A., Razani, G. and Sepidarkish, M. (2020) Maternal and Neonatal Out- 
comes in COVID-19 Infected Pregnancies: A Prospective Cohort Study. Journal of Travel Medicine, 27, taaa158. https://doi.org/10.22541/au.158920850.07965213

[11] Kayem, G., Lecarpentier, E., Deruelle, P., Bretelle, F., Azria, E., Blanc, J., Bohec, C., Bornes, M., Ceccaldi, P.F., Chalet, Y., et al. (2020) A Snapshot of the Covid-19 Pandemic among Pregnant Women in France. Journal of Gynecology Obstetrics and Human Reproduction, 49, Article ID: 101826.

https://doi.org/10.1016/j.jogoh.2020.101826

[12] Sun, G., Zhang, Y., Liao, Q. and Cheng, Y. (2020) Blood Test Results of Pregnant COVID-19 Patients: An Updated Case-Control Study. Frontiers in Cellular and Infection Microbiology, 10, Article ID: 560899. https://doi.org/10.3389/fcimb.2020.560899

[13] McIntyre, H.D. and Moses, R.G. (2020) The Diagnosis and Management of Gestational Diabetes Mellitus in the Context of the COVID-19 Pandemic. Diabetes Care, 43, 1433-1434. https://doi.org/10.2337/dci20-0026

[14] Smati, S., Mahot, P., Bourdiol, A., Ploteau, S., Hadjadj, S. and Cariou, B. (2020) Euglycaemic Ketoacidosis during Gestational Diabetes with Concomitant COVID-19 Infection. Diabetes \& Metabolism. https://doi.org/10.1016/j.diabet.2020.07.008

[15] Gidlöf, S., Savchenko, J., Brune, T. and Josefsson, H. (2020) COVID-19 in Pregnancy with Comorbidities: More Liberal Testing Strategy Is Needed. Acta Obstetricia et Gynecologica Scandinavica, 99, 948-949. https://doi.org/10.1111/aogs.13862

[16] Yang, H., Wang, C. and Poon, L.C. (2020) Novel Coronavirus Infection and Pregnancy. Ultrasound in Obstetrics \& Gynecology: The Official Journal of the International Society of Ultrasound in Obstetrics and Gynecology, 55, 435-437. https://doi.org/10.1002/uog.22006

[17] Torlone, E., Sculli, M.A., Bonomo, M., Di Benedetto, A., Di Cianni, G., Festa, C., Formoso, G., Lapolla, A., Mannino, D., Napoli, A., et al. (2020) Recommendations and Management of Hyperglycaemia in Pregnancy during COVID-19 Pandemic in Italy. Diabetes Research and Clinical Practice, 166, Article ID: 108345. https://doi.org/10.1016/j.diabres.2020.108345

[18] van Gemert, T.E., Moses, R.G., Pape, A.V. and Morris, G.J. (2020) Gestational Diabetes Mellitus Testing in the COVID-19 Pandemic: The Problems with Simplifying the Diagnostic Process. The Australian \& New Zealand Journal of Obstetrics \& Gynaecology, 60, 671-674. https://doi.org/10.1111/ajo.13203

[19] Amaefule, C.E., Sasitharan, A., Kalra, P., Iliodromoti, S., Huda, M.S.B., Rogozinska, E., Zamora, J. and Thangaratinam, S. (2020) The Accuracy of Haemoglobin A1c as a Screening and Diagnostic Test for Gestational Diabetes: A Systematic Review and Meta-Analysis of Test Accuracy Studies. Current Opinion in Obstetrics \& Gynecology, 32, 322-334. https://doi.org/10.1097/GCO.0000000000000648

[20] Codina, M., Corcoy, R. and Goya, M.M. (2020) Update of the Hyperglycemia Gestational Diagnosis during the COVID-19 Pandemic. Endocrinologia, Diabetes $y$ Nutricion, 67, 545-552. https://doi.org/10.1016/j.endien.2020.05.004

[21] Jardine, J., Relph, S., Magee, L.A., von Dadelszen, P., Morris, E., Ross-Davie, M., Draycott, T. and Khalil, A. (2020) Maternity Services in the UK during the COVID-19 Pandemic: A National Survey of Modifications to Standard Care. BJOG: An International Journal of Obstetrics and Gynaecology.

https://doi.org/10.1111/1471-0528.16547

[22] Simmons, D., Rudland, V.L., Wong, V., Flack, J., Mackie, A., Ross, G.P., Coat, S., Dalal, R., Hague, B.M. and Cheung, N.W. (2020) Options for Screening for Gestational Diabetes Mellitus during the SARS-CoV-2 Pandemic. The Australian \& New 
Zealand Journal of Obstetrics \& Gynaecology, 60, 660-666.

https://doi.org/10.1111/ajo.13224

[23] Seshiah, V., Balaji, V., Banerjee, S., Sahay, R., Divakar, H., Jain, R., Chawla, R., Das, A.K., Gupta, S. and Krishnan, D. (2020) Diagnosis and Principles of Management of Gestational Diabetes Mellitus in the Prevailing COVID-19 Pandemic. International Journal of Diabetes in Developing Countries, 40, 329-334.

https://doi.org/10.1007/s13410-020-00860-1

[24] Thangaratinam, S., Cooray, S.D., Sukumar, N., Huda, M.S.B., Devlieger, R., Benhalima, K., McAuliffe, F., Saravanan, P. and Teede, H.J. (2020) Endocrinology in the Time of COVID-19: Diagnosis and Management of Gestational Diabetes Mellitus. European Journal of Endocrinology, 183, G49-G56.

https://doi.org/10.1530/EJE-20-0401 